\title{
Preventing the "Bottoming out and Star-gazing" Phenomenon in Inferior Pedicle Breast Reduction with an Acellular Dermal Matrix Internal Brassiere
}

\author{
João Carlos Sampaio Góes
}

Received: 22 March 2010/Accepted: 22 March 2010/Published online: 29 June 2010

(C) Springer Science+Business Media, LLC and International Society of Aesthetic Plastic Surgery 2010

In the last 22 years we have studied the subject presented by the authors. It is believed that the ptotic breast loses its ability to sustain its shape because the skin and its connective framework become flabby and inefficient causing a high frequency of early recurrence of breast ptosis after mastopexy.

Today, the silicone prosthesis is used in association with mastopexy with the objective of providing a framework and sustainability to the ptotic breast, and with similar frequency for breast augmentation. We observe that nowadays there is an increase in the use of materials to help preserve breast shape post-mastopexy because of the demand from patients.

As the authors have commented, we studied new types of surgical meshes developed from absorbable and partially absorbable suture thread materials. These materials lead to laminar scar tissue that creates a smooth tissue structure sufficient to sustain the breast and which cannot be noticed under palpation and is not visible in mammography, so it does not interfere in the diagnosis of cancer and does not lead to calcification [1].

In my opinion the clinical concerns mentioned about the use of mixed mesh following the principles we advocate are due to lack of clinical experience with it. We know that inclusion of silicone has a considerable number of complications. However, we are prepared to handle them.

As Brown et al. have proposed, I developed a 5-year follow-up study of the permanent integration of organic material to sustain the breast using a personal periareolar mammaplasty technique [2]. I observed that the use of organic material caused a reaction in some cases that implied a scar complication. This was not observed when mixed mesh was used in over 600 surgical cases. Mixed mesh has been demonstrated to be stable and efficient for many years, maintaining the postsurgical result with no recurrence of ptosis. Because organic materials are more elastic and form scars late, they have to be observed and evaluated more extensively with respect to their stability and efficiency in sustaining breasts in the late postsurgical follow-up. Also, cost, material access, and quality control are aspects that favor mixed mesh.

I want to congratulate the authors for the quality of their work and the contribution to the subject.

\section{References}

1. Góes JC, Landecker A, Lyra EC, Henríquez LJ, Góes RS, Godoy PM (2004) The application of mesh support in periareolar breast surgery: clinical and mammographic evaluation. Aesthetic Plast Surg 28:268-274

2. Góes JC, Bates D (2009) Periareolar mastopexy with FortaPerm. Aesthetic Plast Surg 34(3):350-358

\footnotetext{
J. C. S. Góes ( $₫)$

Rua Campos Bicudo, 98-conj. 111, Sao Paulo, SP 04536-010, Brazil

e-mail: clinica@sampaiogoes.com
} 